\title{
СТРУКТУРНЫЙ АНАЛИЗ И ТИПОЛОГИЯ АКТОРОВ В НАРРАТИВНОЙ КУЛЬТУРЕ
}

\begin{abstract}
Аннотация. Разрабатывается метод структурного анализа и новая типология диегетических лиц (акторов) в произведениях повествовательных и миметических нарративных форм. Для построения типологии акторов предлагается использовать понятие характера, которое не может быть механически перенесено из психологии в теорию нарративной культуры, поскольку вымышленные акторы не имеют референта вне диегетического мира и, строго говоря, не имеют психики. Однако акторов удается редуцировать к совокупности характерологических признаков. Это позволяет ввести понятие структуры характера актора. Как следствие, возникает новая типология акторов в зависимости от структуры иххарактеров - выделяются акторы, соответственно, с о-характером, с простым характером и со сложным характером. Вводятся представления о глубине характера актора, об основных разновидностях характерологических систем и о размерности характерологического пространства. Предлагается способ количественного определения характерологической близости акторов путем сопоставления им точек в многомерном пространстве.

Ключевые слова: философия, культурология, актор, диегетическое лицо, нарративная культура, структурный анализ, структурализм, семиотика, структура характера актора, типология акторов, художественный дискурс.
\end{abstract}

\section{1. Постановка проблемы}

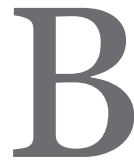
современной культурологии нарратив все чаще рассматривается как особая форма структурирования и подачи информации, которая специфическим образом организует наше восприятие. Согласно этому взгляду, информация, накопленная в культуре, эффективней всего усваивается человеческим сознанием, если выражена в повествовательной или миметической нарративной форме. Более того: «...нарративность лежит в основе самого нашего понятия об истине: так, последние исследования в области правового дискурса показывают, что тем свидетелям, чьи показания ближе всего подходят к архетипическим моделям рассказа, поверят в суде скорее, чем другим» ${ }^{1}$.

Следуя В. Шмиду, мы различаем 1) повествовательную нарративную культуру, доносящую информацию в нарративной форме посредством повествователя (устные и письменные мифы, легенды, баллады, рассказы, романы, анекдоты,

${ }^{1}$ Мартин Б., Рингхэм Ф. Словарь семиотики. М.: ЛИБРОKOM, 2010. C. 25. сказки и т.д.), и 2) миметическую нарративную культуру, доносящую информацию в нарративной форме без посредства повествователя, но с помощью «подражания» (иконических знаков) $)^{2}$.

В миметической нарративной культуре в свою очередь можно выделить экранные (кинематограф, телевидение, рекламные ролики, анимационные фильмы, компьютерные игры и т.д.), сценические (театр, балет, пантомима, опера и т.д.) и другие формы (нарративная живопись, комиксы, радиоспектакли, нарративная скульптура и т.д.).

Все эти культурные феномены сближает способ структурирования доносимой информации. Как установил В. Шмид, на уровне диегетического (т.е. изображаемого в произведении) мира они обладают темпоральной структурой и отражают изменение состояния хотя бы одного действующего (или претерпевающего воздействие) диегетического лица 3 .

\footnotetext{
2 Шмид В. Нарратология. 2-е изд. М.: Языки славянской культуры, 2008. С. 21.

3 Там же. С. 13-16.
} 


\section{Философия и культура 8(68) • 2013}

Чтобы создать единый научный язык для описания нарративной культуры в ее разнообразных проявлениях, необходимо разработать удобную типологию диегетических лиц, фигурирующих в диегетических мирах.

Очевидно, что к решению указанной проблемы можно подойти с нескольких сторон. Наиболее продуктивной оказалась классификация диегетических лиц в зависимости от их нарративных функций, или ролей. Диегетические лица, рассмотренные в таком ключе, сегодня принято называть актантами 4 . В.Я. Пропп в книге «Морфология волшебной сказки» (1928) выделил тридцать одну функцию, которые распределены между семью «кругами действий», таких как вредитель, даритель, помощник и т.д. ${ }^{5}$ А. Ж. Греймас выявил фундаментальную универсальную нарративную структуру, присущую всем феноменам нарративной культуры, и свел семь пропповских «кругов действий» к трем парам бинарных оппозиций (субъект/объект; отправитель/получатель; помощник/оппонент), или шести актантным ролям ${ }^{6}$. Эти роли могут исполнять диегетические люди, места, предметы или абстрактные понятия7. Можно заключить, что работа по созданию типологии актантов в общих чертах завершена.

Но диегетических лиц можно рассматривать и классифицировать не только на уровне фундаментальной универсальной нарративной структуры, где определяются их актантные роли, но и на дискурсивном уровне. В этом случае диегетические лица, как правило, называют акторами ${ }^{8}$. Б. Мартин и Ф. Рингхэм пишут: «именно на этом $<$ дискурсивном> уровне актанты получают имена и становятся акторами, принимая тематические роли, такие как “сын”, “отец” или “солдат”, задействованные трансформации выстраиваются в хронологические последовательности и помещаются в заданное пространство, а объекты,

\footnotetext{
${ }^{4}$ Мартин Б., Рингхэм Ф. Словарь семиотики. М.: ЛИБРОKOM, 2010. С. 35-36.

5 Пропп В.Я. Морфология волшебной сказки. М.: Лабиринт, 2001.

${ }^{6}$ Греймас А.Ж. Структурная семантика: Поиск метода. М.: Академический Проект, 2004. Гл. «Размышление об актантных моделях». С. 248-277.

7 Греймас А.Ж., Курте Ж. Семиотика: объяснительный словарь теории языка // Семиотика / Сост. Ю.С. Степанов. М.: Радуга, 1983. С. 484.

${ }^{8}$ Мартин Б., Рингхэм Ф. Словарь семиотики. М.: ЛИБРОKOM, 2010. C. 37-38.
}

являющиеся предметом поиска, объединяются в системы ценностей, которые организуют высказывание и определяют направление стремлений и конфликтов»9.

Удобной типологии акторов до сих пор не предложено, хотя существуют несколько конкурирующих подходов. Очевидно, акторов можно поделить на одушевленные и неодушевленные, антропоморфные и неантропоморфные, абстрактные и неабстрактные. Неодушевленные акторы чаще всего встречаются в произведениях для детей (можно вспомнить сказку братьев Гримм «Соломинка, уголек и боб»). Неантропоморфные акторы - это, например, ксеноморфы в фильме Ридли Скотта «Чужой» и его продолжениях. Абстрактные акторы - это, например, Власть и Сила (Насилие) в трагедии Эсхила «Прометей прикованный». Акторов можно поделить в зависимости от их социального или классового статуса в диегетическом мире - например, члены семьи Палмер в телесериале «Твин Пикс» являются представителями среднего класса.

Но самый перспективный подход к типологии акторов в нарративной культуре выстраивается по аналогии с типологией людей. Это закономерно, поскольку люди - это и создатели, и потребители нарративной культуры. Совокупность поведенческих особенностей человеческого индивидуума называется характером. Однако есть важная причина, по которой понятие характера не может быть механически перенесено из психологии в теорию нарративной культуры.

В повествовательной нарративной культуре у вымышленных акторов заведомо нет психики, поскольку они представляют собой, по сути, последовательность языковых символов - акустических в случае устного повествования или визуальных в случае письменного повествования.

Но нет психики и у вымышленных акторов в миметической нарративной культуре. Психика исполнителя главной роли в балете «Щелкунчик» на сцене Мариинского театра в 1929 году - это психика балетного танцовщика Петра Гусева, а не психика сценического актора - куклы для раскалывания орехов по имени Щелкунчик. Психика исполнительницы роли обаятельной американской школьницы в приквеле к телесериалу «Твин Пикс»это психика актрисы Шерил Ли, а не психика экранного актора - Лоры Палмер.

\footnotetext{
9 Там же. С. 68.
} 


\section{Структурализм}

У вымышленных акторов нет психики и, следовательно, не выполнено conditio sine qua non психологического подхода. Поэтому проблема типологии акторов в нарративной культуре не относится к сфере психологии.

Проблема типологии акторов в нарративной культуре не относится и к филологии, поскольку мы имеем дело не только с вербальными языками. При анализе нарративной культуры нам приходится сталкиваться с акторами и в произведениях, включающих невербальные элементы, - театральных спектаклях, кинофильмах, телесериалах, paдиоспектаклях, балетах, пантомимах, графических новеллах, мультфильмах, компьютерных играх, телерекламе и нарративной живописи. Конечно, если под текстом понимать «всякий связный знаковый комплекс» (М.М. Бахтин) $)^{10}$, то мы имеем дело только с текстами различной природы. Но такое «поглощение» теории культуры филологией едва ли оправдано.

Актуальность исследования сложно переоценить, поскольку акторы являются неотъемлемыми элементами нарративной культуры, многоуровневая связь акторов играет важную роль в функционировании нарративной культуры как целого. Но без создания удобной и логичной типологии акторов невозможно создание единого научного метаязыка, необходимого для описания, анализа и реконструкции разнообразных феноменов нарративной культуры.

\section{2. Общая семиотическая формула структурного анализа характеров акторов}

В. Райх ввел представление о структуре характера как о своеобразной динамической основе личностных особенностей человека, фиксирующих социальные условия воспитания и существования ${ }^{11}$.

В том же смысле этот термин использовал его ученик А. Лоуэн. Структуру характера он определял как «застывшую функцию» ${ }^{12}$, которая «отображает только ту модальность, в которой спо-

\footnotetext{
${ }^{10}$ Бахтин М.М. Проблема текста в лингвистике, филологии и других гуманитарных науках // Бахтин М.М. Эстетика словесного творчества. 2-е изд. М.: Искусство, 1986. С. 297.

${ }^{11}$ Райх В. Анализ характера. М.: Апрель Пресс, ЭКСМОПресс, 2000.

12 Лоуэн А. Физическая динамика структуры характера. М.: Компания ПАНИ, 1996. С. 96.
}

собна функционировать инстинктивная жизнь» 13 . Лоуэном исследовалось, как «травматические переживания ранних лет жизни, раскрываемые в психоаналитическом исследовании невротического поведения, детерминируют структуру характера» ${ }^{14}$.

Мы подразумеваем под структурой характера актора принципиально иное. Динамика присуща характеру только живущего человека. По нашему убеждению, из понятия структуры характера актора следует исключить всякое представление о динамике. После того, как в художественном произведении поставлена точка, актор не развивается и представляет собой лишь фиксированную совокупность характерологических признаков. «Когда мы читаем книгу, конец уже дописан», настаивает В.П. Руднев и редуцирует сюжет к композиции ${ }^{15}$. Мы аналогичным образом редуцируем актора к совокупности характерологических признаков.

Характерологические признаки любого актора можно разбить на логические классы, соответствующие типам характера в выбранной характерологической системе. Результат этой процедуры мы называем структурой характера актора, а саму процедуру - структурным анализом характера актора.

Наиболее удовлетворительное определение того, что считать «структурой» было дано математиками, выступающими под коллективным псевдонимом Н. Бурбаки: «Теперь можно объяснить, что надо понимать в общем случае под математической структурой. Общей чертой различных понятий, объединенных этим родовым названием, является то, что они применимы к множеству элементов, природа которых не определена. Чтобы определить структуру, задают одно или несколько отношений, в которых находятся его элементы <...>; затем постулируют, что данное отношение или данные отношения удовлетворяют некоторым условиям (которые перечисляют и которые являются аксиомами рассматриваемой структуры). Построить аксиоматическую теорию данной структуры - это значит вывести логические следствия из аксиом структуры, отказавшись от каких-либо других предположений относительно рассматриваемых

\footnotetext{
13 Там же. С. 101.

14 Там же. С. 132.

15 Руднев В.П. Прочь от реальности: Исследование по философии текста. М.: Аграф, 2000. С. 173.
} 


\section{Философия и культура 8(68) • 2013}

элементов (в частности, от каких-либо гипотез относительно их “природы”)» ${ }^{16}$.

В гуманитарных науках структурный анализ может быть определен аналогичным образом. Как уточняет В. Декомб: «Иными словами, структурный анализ исходит из структуры, т. е. из связей, определяемых чисто формально некоторыми качествами, которыми обладает совокупность элементов, чья природа не уточняется; опираясь на заданную таким образом структуру, этот анализ показывает, что такое-то культурное содержание (система родства, миф) является ее моделью или, как еще говорят, "репрезентацией”. Что же доказывается в данном случае? А вот что, ни больше, ни меньше: это содержание изоморфно определенному числу других содержаний. И структура как раз то, что сохраняется в изоморфизме между двумя совокупностями» ${ }^{17}$.

Основным понятием структурного анализа служит структурная единица, которая выполняет одну из простейших функций моделируемого объекта. Р. Барт писал: «Поскольку любая система представляет собой комбинацию единиц, входящих в известные классы, необходимо в первую очередь расчленить повествовательный текст и выделить такие сегменты повествовательного дискурса, которые можно распределить по небольшому числу классов; короче, нужно определить минимальные повествовательные единицы» ${ }^{18}$. Этот подход применим не только в отношении литературных акторов, но и в отношении экранных и сценических акторов. При структурном анализе характеров акторов минимальной структурной единицей является характерологический признак.

Воспользуемся второй трихотомией знаков Пирса, или делением знаков на иконические знаки, индексы и символы. Индексы в этом случае определяются как знаки, зависимые «от своего объекта в силу отношений пространственно-временной связи или причинности» ${ }^{19}$. В этом смысле дым есть индекс огня.

16 Бурбаки Н. Архитектура математики // Бурбаки Н. Очерки по истории математики. М.: Изд-во иностранной литературы, 1963. С. 251.

17 Декомб В. Современная французская философия. М.: Весь Мир, 2000. С. 85.

18 Барт Р. Введение в структурный анализ повествовательных текстов // Барт Р. Нулевая степень письма. М.: Академический Проект, 2008. С. 362.

19 Peirce C.S. Collected Papers, vols. 1-6, ed. C. Hartshorne \& P. Weiss, vols. 7-8, ed. A. W. Burks. Cambridge (Mass.): Harvard Univ. Press, 1931-1958. 2.293. См. также: Нёт В. Чарлз Сандерс Пирс // Критика и семиотика, № 3/4, 2001. С. 5-32.
В русском языке в этом же значении используются термины «индексные знаки» (Р.О. Якобсон) и «индексальные». В. Шмид в аналогичном значении использует термины «индициальные знаки», или «симптомы» ${ }^{20}$.

Характерологические признаки являются индексами, поскольку отсылают к характеру, с которым связаны причинно-следственной связью, аналогично тому, как дым связан с огнем, а симптомы - с болезнью. Причем, как подчеркивает Барт, корреляты этих индексов «всегда располагаются “выше”, чем они сами; иногда даже они остаются виртуальными, не входя ни в какую бы то ни было эксплицитную синтагму (“характер” персонажа можно прямо ни разу не назвать, но все время указывать на него) $<\ldots . »^{21}$.

Теперь можно вывести общую семиотическую формулу структурного анализа характеров акторов. Утверждение, что между планом выражения (E) и планом содержания (C) существует отношение (R), в символической записи, предложенной Л. Ельмслевым, выглядит так: $\mathrm{ERC}^{22}$. Барт показал, что знаковая система ERC может служить планом выражения, или означающим, некоторой второй знаковой системы, что можно записать как (ERC) $\mathrm{RC}^{23}$. В нашем случае в качестве плана выражения второй знаковой системы следует рассматривать произведение нарративной культуры, а в качестве плана содержания второй знаковой системы совокупность характерологических признаков акторов.

Поскольку отношение $\mathrm{R}$ в данном случае отсылает к различным планам содержания - соответственно, первого и второго уровня, - целесообразно добавить обозначения уровней. Получаем для системы характерологических признаков следующую семиотическую формулу: $\left(\mathrm{E}_{1} \mathrm{RC}_{1}\right) \mathrm{RC}_{2}$. Таким образом, система характерологических признаков акторов является коннотативной системой в терминах Ельмслева и Барта, т. е. «системой, план выражения которой сам является знаковой системой» ${ }^{24}$.

\footnotetext{
${ }^{20}$ Шмид В. Нарратология. 2-е изд. М.: Языки славянской культуры, 2008. С. 46.

${ }^{21}$ Барт Р. Введение в структурный анализ повествовательных текстов // Барт Р. Нулевая степень письма. М.: Академический Проект, 2008. С. 366.

22 Барт Р. Основы семиологии // Барт Р. Нулевая степень письма. М.: Академический Проект, 2008. С. 308.

23 Там же. С. 341.

24 Там же.
} 
Структурный анализ характеров акторов является, по сути, метаязыком, позволяющим описывать системы характерологических признаков, и, таким образом, представляет собой третью знаковую систему. В символической записи Ельмслева и Барта метаязык обозначается как ER(ERC). Подставляя теперь вместо плана содержания метаязыка семиотическое выражение, полученное для системы характерологических признаков, и расставляя обозначения уровней, имеем:

$$
E_{3} R\left[\left(E_{1} R C_{1}\right) R C_{2}\right]
$$

Это и есть общая семиотическая формула структурного анализа характеров акторов, справедливая как для повествовательных, так и миметических нарративных произведений.

Заметим, что этой же семиотической формулой описывается структурный анализ мифов, разработанный К. Леви-Стросом: «Поскольку сами мифы основаны на кодах второго порядка (коды первого порядка - те, из которых состоит язык), книга эта может рассматриваться как набросок кода третьего порядка, предназначенного для обеспечения взаимопереводимости многих мифов» 25 .

\section{3. Характерологические координаты актора}

Можно предложить логико-математический аппарат для формализации предлагаемого подхода. Допустим, что мы выбрали характерологическую систему с $\mathrm{N}$ базовыми типами характера. Характерологические признаки актора Y мы распределяем по логическим классам, соответствующим базовым типам характера, и подсчитываем. Причем один и тот же характерологический признак может принадлежать одному, двум и более логическим классам - но не всем, иначе это не характерологический признак, а антропологическая константа.

Эту процедуру хорошо описал Б.И. Ярхо: «Результатом этого является анализ, в идеале имеющий форму ведомости, в которую занесены все рубрики выделенных признаков. <...> но перед тем, как стать ведомостью (опять-таки в идеале) проходит через стадию картотеки. В этом виде он,

25 Леви-Строс К. Мифологики: Сырое и приготовленное. М.: Флюид, 2006. С. 21. пожалуй, действительно напоминает химический анализ, ибо на картотеке вы видите только диспаратные части целого. Разница только в том, что целое продолжает существовать рядом со своим анализом, - разница, впрочем, несущественная, ибо ведь и химик оставляет в мире достаточный запас неразложенного вещества» ${ }^{26}$.

Пусть $\mathrm{p}_{\mathrm{i}}-$ количество характерологических признаков і-го типа характера у актора Ү. Тогда актору Y можно поставить в соответствие вектор $\left\{\mathrm{p}_{1}, \mathrm{p}_{2} \ldots \mathrm{p}_{\mathrm{N}}\right\}$.

Поскольку число характерологических признаков у актора может быть очень велико, этот вектор желательно нормировать. Обозначим нормированный вектор $\left\{\lambda_{1}, \lambda_{2} \ldots \lambda_{\mathrm{N}}\right\}$. В Евклидовой метрике характерологические координаты $\lambda_{1}$ можно определить по формуле:

$$
\lambda_{i}=\frac{p_{i}}{\sqrt{\sum_{i=1}^{N} p_{i}^{2}}}
$$

Если актор не имеет характерологических признаков, т. е. все $\mathrm{p}_{\mathrm{i}}$ равны нулю, то все $\lambda_{\mathrm{i}}$ также считаются равными нулю. Совокупность из $\mathrm{N}$ характерологических координат адекватно описывает структуру характера актора Y.

В зависимости от соотношений между характерологическими координатами можно выделить о-характер, простой характер и сложный характер.

Df. Актор Y имеет o-характер, если все его характерологические координаты равны нулю.

$\boldsymbol{D} \boldsymbol{f}$. Актор Ү имеет простой характер, если какаято из его характерологических координат намного больше всех остальных (унимодальное распределение характерологических признаков).

$\boldsymbol{D f}$. Актор Ү имеет сложный характер, если об акторе Y нельзя сказать, что он имеет о-характер и простой характер (бимодальное или мультимодальное распределение характерологических признаков).

Df. Характерологический радикал - совокупность характерологических признаков і-го типа в структуре сложного характера.

Само по себе существование сложных характеров не новость. По мнению А.Е. Личко, сложные (он их называет «смешанными») типы

\footnotetext{
26 Ярхо Б. И. Методология точного литературоведения. М.:
} Языки славянских культур, 2006. С. 67. 


\section{Философия и культура 8(68) • 2013}

довольно распространены, весьма разнообразны и представляют «почти половину случаев явных акцентуаций характера и более половины психопатий» ${ }^{27}$. Личко даже предложил остроумную графическую репрезентацию совместимости в одной личности двух типов акцентуаций ${ }^{28}$. А. Лоуэн писал: «Определить тип характера не всегда легко. Поскольку структура характера большинства людей содержит как минимум два элемента, приходится выявлять доминирующий фактор личности. Кроме досконального знания динамики каждого типа, необходим значительный клинический опыт. Границы часто бывают смазаны ${ }^{29}$. Таким образом, и Леонгард, и Личко, и Лоуэн признавали существование у людей сложных типов характера, включающих, как минимум, два радикала. Но исчерпывающей типологии сложных характеров они не дали.

Типология сложных характеров людей действительно представляет собой проблему, поскольку «черты одних типов сочетаются друг с другом довольно часто, а других практически никогда» ${ }^{\circ}$. В большинстве характерологических систем типология сложных характеров является эмпирической и постоянно пополняемой, поскольку мы не можем априорно сказать, какие сложные характеры встречаются у людей, а какие нет.

Но в характерах акторов любые характерологические признаки являются совместными. Доказывается это прямым конструированием акторов с соответствующими сочетаниями характерологических признаков. Следовательно, можно предложить априорную дедуктивно-аксиоматическую типологию сложных характеров акторов.

\section{4. Типология сложнив характеров акторов}

Необходимость введения сложных характеров связана с тем, что базовых типов характеров оказывается недостаточно для дифференцированного описания сколько-нибудь значительного количества случаев, даже если мы не сильно отдаляемся от нормы.

27 Личко А. Е. Психопатии и акцентуации характера у подростков. СПб: Речь, 2010. С. 137.

28 Там же. С. 138-139.

29 Лоуэн А. Физическая динамика структуры характера. М.: Компания ПАНИ, 1996. С. 128.

30 Там же.
Проблема при этом решается двумя способами: 1) либо в характерологическую систему вводятся все новые и новые базовые типы характеров; 2) либо типология базовых характеров дополняется типологией сложных характеров. При этом часто говорят не о сложных характерах, а о характерах смешанных, промежуточных, амальгамных, молекулярнъц, композитных, комбинированных, мозаччных, полифонических и т. д.

Первый путь ведет к появлению громоздких, неудобных для практического использования типологий, число базовых характеров в которых доходит до 100 и более. Уже у Теофраста их было тридцать ${ }^{31}$, а Ш. Фурье насчитал уже 810 главных характеров $^{32}$.

Более экономным и удобным в практическом отношении является второй путь, поскольку, изучив базовые типы характеров, нетрудно составить представление об их комбинациях. Это подталкивает к поиску конструктивного принципа, устанавливающего соответствие между типологией базовых характеров и типологией сложных характеров.

Прежде, чем приступить к поиску, следует сформулировать критерии, которым должна удовлетворять типология сложных характеров акторов.

Основных критериев, по нашему мнению, три:

1) типология сложных характеров акторов должна выводиться из типологии базовых характеров акторов логико-дедуктивным путем (это означает, что сама процедура не зависит от того, какую совокупность базовых характеров мы используем);

2) типология сложных характеров акторов должна отличаться логичностью, простотой, компактностью, быть удобной в практическом использовании;

3) типология сложных характеров акторов должна обладать предсказательной силой (т.е. в каком-то смысле представлять собой аналог таблицы Менделеева).

Большим подспорьем является эвристическая гипотеза: каждый сложный характер реализуется в диалоге, триалоге, тетралоге и т.д. базовых характеров. Поэтому имеет смысл рассматривать все возможные сочетания базовых характеров.

\footnotetext{
31 Феофраст (Теофраст). Характеры. СПб: Азбука-классика, 2010.

32 Фурье Ш. Теория четырех движений и всеобщих судеб // Фурье Ш. Избранные произведения: в 3 т. М.: Государственное социально-экономическое издательство, 1938-1939. Т. І. С. 108.
} 
Диальными характерами мы будем называть сложные характеры, реализующиеся в диалоге (естественно, двух) базовых характеров. Триальными характерами - соответственно, сложные характеры, реализующиеся в триалоге базовых характеров. Тетральными - сложные характеры, реализующиеся в тетралоге базовых характеров. Аналогично определяются пентальные, гексальные, гептальные и т.д. сложные характеры.

Теперь дадим формальные дефиниции.

Df. Актор Y имеет диальный характер, если в его структуре присутствуют два радикала (бимодальное распределение характерологических признаков).

Точно так же у акторов определяются сложные характеры высших порядков, только в структуре триального характере обнаруживается три радикала, тетрального - четыре и т. д.

Число типов сложных характеров $k$-го порядка в характерологической системе, включающей $\mathrm{N}$ базовых типов характеров, равно числу сочетаний по $k$ из $\mathrm{N}$ :

$$
C_{N}^{k}=\frac{N !}{k !(N-k) !}
$$

Теорема. Общее число типов характеров акторов в характерологической системе с $\mathrm{N}$ базовыми типами характеров равно $2^{\mathrm{N}}$.

Доказательство: число характеров из $k$-радикалов равно количеству сочетаний по $k$ из $\mathrm{N}$, но сочетания по $k$ из $\mathrm{N}-$ это коэффициенты в биноминальном разложении $(1+1)^{\mathrm{N}}$. Что и требовалось доказать.

Интересно, что предложенный подход можно использовать и для типологии сложных характеров людей, только в этом случае общее число типов характеров людей будет равно $2^{\mathrm{N}}-1$. Единицу надо вычесть потому, что у людей не существует так называемого o-характера (не содержащего в себе ни одного радикала), который в любой характерологической системе выполняет функцию аналогичную функции нулевого вектора в линейной алгебре ${ }^{33}$. Эмпирически невозможный у людей «нулевой характер» однако полезен как теоретическая абстракция. У акторов же о-характер встречается. Им обладают акторы, о которых только упоминается, но не сообщается никаких подробностей.

\footnotetext{
33 Бойко М.Е., Руднев В.П. Реализм и характер // Знание. По-
} нимание. Умение. 2011. № 3.
Таким образом мы получаем аналог таблицы Менделеева для сложных характеров акторов. Вероятно, не для всех ячеек этой характерологической таблицы можно подобрать пример из произведений мировой культуры. Но это и неважно. Как подчеркивал основоположник культурологии Л.А. Уайт, корректным определением является то, с помощью которого можно определить «предмет "х" принадлежит или не принадлежит классу "у” независимо от количества предметов "x" (логически рассуждая, класс может состоять лишь из одного компонента или даже не иметь их вообще)» ${ }^{34}$.

Более того, именно априорные типологии с наибольшим количеством пустых классов, обладают наибольшим эвристическим потенциалом. Подобно тому, как пустые клетки в таблице Менделеева указывают на еще не открытые элементы, пустые клетки в характерологической таблице указывают на теоретически представимые, но пока не зафиксированные типы характеров. Таким образом, типология характеров акторов подсказывает путь, который может оказаться плодотворным и применительно к типологии характеров людей.

Введем еще один термин.

Df. Глубина (D) характера актора $\mathrm{Y}$ - это количество радикалов в структуре характера актора Y.

Очевидно, что $\max (D)=N$. Глубина простого характера, естественно, равна единице. Глубина о-характера равна нулю.

Сложные характеры с максимальной глубиной образуют всего один тип (включает все возможные радикалы). Чем глубже характер, тем более он неоднозначен, тем сложнее его «схватить», т. е. наше значение термина «глубина» применительно к акторам не слишком отличается от повседневного употребления этого слова в отношении людей.

\section{5. Метатипология характеров акторов}

Важно подчеркнуть, что развиваемый подход применим вне зависимости от того, какую характерологическую систему мы используем. Но возможности структурного метода анализа характеров акторов, конечно, зависят от выбранной характерологической системы.

34 Уайт Л.А. Понятие культуры // Антология исследований культуры. Т. 1. СПб: Университетская книга, 1997. С. 38. 


\section{Философия и культура 8(68) • 2013}

Это замечание тем более актуально, что к настоящему времени существует несколько десятков характерологических систем. Так что впору создавать типологию типологий характеров, т. е. метатипологию характеров. Для нас принципиально деление типологий характеров на два метатипа: открытые и закрытые.

Пусть в характерологической системе $\mathrm{S}$ существует K типов характера и $\mathrm{T}_{\mathrm{i}}-$ экстенсионал ${ }^{35} \mathrm{i}$-го типа характера. Число K, очевидно, равно сумме простых и сложных типов характера в данной типологии. Тогда можно дать определения.

$\boldsymbol{D} \boldsymbol{f}$. Характерологическая система $\mathrm{S}$ является закрытой тогда и только тогда, когда объединение (конъюнкция) экстенсионалов всех описанных в ней типов характеров образует универсальное множество (людей или акторов).

Df. Характерологическая система S является открытой тогда и только тогда, когда она не является закрытой.

Смысл этого деления интуитивно понятен. В открытых типологиях допускается, что существуют еще неописанные типы характера. Это не означает, что мы способны предъявить объект, который не можем отнести ни к одному из описанных типов, речь идет о теоретической возможности обнаружения такого объекта - человека или актора. Это не пустая абстракция, поскольку мы не можем полностью исключить, что социальные трансформации и научно-технические прогресс постоянно вызывают появление новых, ранее не описанных характеров. Этот процесс и его отражение в характерологии можно обозначить термином «характерозис» (по аналогии с терминами «семиозис», «диагнозис» и т.д.).

Закрытые характерологические системы получаются, как правило, логическим делением универсального множества объектов (в нашем случае людей или акторов), т.ч. любой объект заведомо относится к одному из зафиксированных типов, даже если сложно определить к какому именно. Заметим, что сама наша метатипология является закрытой.

К открытым характерологическим системам относятся типологии характеров Теофраста, 3. Фрейда, В. Райха, А. Лоуэна, П.Ф. Лесгафта, П.Б. Ганнушкина, К. Леонгарда, А.Е. Личко, М.Е. Бурно и др.

\footnotetext{
35 Карнап Р. Значение и необходимость: Исследование по се-
} мантике и модальной логике. 2-е изд. М.: ЛКИ, 2007. С. 52.
К закрытым характерологическим системам относятся типологии М. Дессуара, Н. О. Лосского, А. Адлера, К.Г. Юнга, У. Шелдона, К. Бриггс и И. Майерс, Д. Кейрси, К. Хейманса и Р. Ле Сенна, А. Аугустинавичюте и др.

Заметим, что самой простой способ образования закрытых характерологических систем - это бинарные оппозиции. Например, в характерологической системе Хейманса и Ле Сена рассматриваются различные комбинации из трех признаков: эмоциональности (+ или -), активности (+ или -), Первичности/Вторичности. В результате возникает восемь типов характера ${ }^{36}$. В принципе можно выбрать сколь угодно много логически независимых бинарных оппозиций.

\section{6. Характерологическая близость акторов}

Но есть еще один очень полезный теоретический конструкт - замкнутые типологии. Замкнутые характерологические системы - это открытые характерологические системы или их подсистемы, рассмотренные так, как будто они являются закрытыми, т. е. игнорируются еще неописанные, незафиксированные типы характеров или какие-то неактуальные подсистемы.

Этот конструкт нам нужен для того, что сформулировать, пожалуй, самое интересное следствие из нашей метатипологии. Оказывается, при использовании закрытых и замкнутых характерологических систем можно количественно выразить характерологическую близость акторов.

Для этого выделим в закрытой или замкнутой характерологической системе подсистему базовых характеров. Важное ограничение накладываемое на эту подсистему заключается в том, чтобы базовые характеры были логически независимы. Как правило, создатели типологий характера сознательно или бессознательно выполняют это условие. Исключение представляют собой, например, система Юнга и ее производные (Индикатор типов личности Майерс-Бриггс, соционика).

Тогда по аналогии с векторным пространством в математике, можно ввести представление о $\mathrm{N}$-мерном характерологическом пространстве, базисом которого является совокупность базовых характеров. Количество базовых характеров мы будем называть размерностью данной характеро-

\footnotetext{
${ }^{36}$ Психология и психоанализ характера / Ред.-сост. Д.Я. Райгородский. 5-е изд. Самара: Бахрах-М, 2009. С. 327.
} 
логической системы $(\operatorname{dim} S)$. Если в $S$ выделяется N базовых характеров, то $\operatorname{dim} S=N$.

Развивая математическую аналогию, можно сказать, что данная выборка $\mathrm{N}$ характеров только тогда образует базис характерологического пространства, когда ни один из этих характеров не может быть представлен как линейная комбинация остальных $(N-1)$ характеров.

Сегодня уже получили широкое признание модели репрезентации, «в которых каждый объект задается в виде точки в многомерном пространстве» ${ }^{37}$. Примером может служить геометрическая модель для определения близости D между стимулами ${ }^{38}$. Близость между стимулами а и b вычисляется по формуле для обобщенной меры расстояний Германа Минковского:

$$
D(a, b)=\left[\sum_{i=1}^{N}\left(a_{i}-b_{i}\right)\right]^{/ r}
$$

где $\mathrm{N}$ задает размерность многомерного пространства, a r - метрику этого пространства.

При r=1 мы имеем дело с так называемой «манхэттенской» метрикой (ее еще называют метрикой «городских кварталов», англ. city-block).

Чаще всего полагается, что $\mathrm{r}=2$. Это привычная нам Евклидова метрика, согласно которой расстояние между двумя точками в многомерном пространстве определяется по теореме Пифагора ${ }^{39}$.

Другой пример - метод семантического дифференциала ${ }^{40}$, позволяющий количественно выразить расстояние между коннотативными значениями понятий путем сопоставления им точек в многомерном пространстве. Расстояние в этом случае вычисляется по формуле:

$$
D(x, y)=\sqrt{\sum_{1}^{N} d\left(x_{i}, y_{i}\right)^{2}}
$$

\footnotetext{
37 Когнитивная психология / под ред. В.Н. Дружинина, Д.В. Ушакова. М.: ПЕР СЭ, 2002. С. 120-121.

${ }^{38}$ Shepard R. Multidimentional scaling, free-fitting, and clustering // Science. 1980. Vol. 210. P. 390-398.

39 Шрейдер Ю.А. Что такое расстояние? М.: Физматгиз, 1963. С. 27; Скворцов В.А. Примеры метрических пространств. М.: Изд-во Московского центра непрерывного математического образования, 2002. С. 5.

${ }^{40}$ Osgood C.E., Suci G.J., Tanenbaum P.N. The Measurement of Meaning. Urbana, University of Illinois Press, 1957.
}

где $\mathrm{D}(\mathrm{x}, \mathrm{y})$ - расстояние между точками, представляющими значение слов х и $\mathrm{y} ; \mathrm{d}\left(\mathrm{x}_{\mathrm{i}}\right.$, $\left.\mathrm{y}_{\mathrm{i}}\right)$ - разность между координатами $\mathrm{x}$ и у на факторе i. Суммирование производится по всем факторам ${ }^{41}$.

В закрытых и замкнутых характерологических системах с логически независимыми базовыми характерами, используя процедуру многомерного шкалирования, можно количественно определить характерологическую близость $D(X, Y)$ акторов $\mathrm{X}$ и Y. Представим акторов в виде нормированных векторов, состоящих из характерологических координат $\lambda_{1}$. Тогда в Евклидовой метрике:

$$
D(X, Y)=\sqrt{\sum_{i=1}^{N}\left(\Lambda_{i}(X)-\lambda_{i}(Y)\right)^{2}}
$$

где $\lambda_{\mathrm{i}}-\mathrm{i}$-тая характерологическая координата. Очевидно, что

$$
0 \leq D(X, Y) \leq \sqrt{N}
$$

На этом мы остановимся, перенося сожаление К.Г. Юнга с психологии на теорию культуры: «Трагично то, что у психологии нет никакой математики, всюду совпадающей с ней. Тем самым она лишена той самой неизмеримой благодати архимедовой точки, которую вкушает физика» ${ }^{42}$.

\section{7. Заключение}

Мы показали, как структурный анализ позволяет осуществить типологизацию акторов в нарративной культуре. Принципиально важно, что область применения данного подхода охватывает как культурные феномены, имеющие повествовательную нарративную форму, так и культурные феномены, имеющие миметическую нарративную форму, в том числе экранные и сценические искусства. При этом подчеркивается, что диегетические лица (акторы) - это сущности особой природы, которые имеют иной онтологический статус, чем живые люди, и на которые невозможно механиче-

\footnotetext{
${ }^{41}$ Искусствометрия: Методы точных наук и семиотики / Ред. и сост. Ю.М. Лотмана, В.М. Петрова. 4-е изд. М.: ЛИБРОKOM, 2009. С. 358-359.

${ }^{42}$ Юнг К.Г. Об энергетике души. М.: Академический Проект, 2010. C. 255.
} 


\section{Философия и культура 8(68) • 2013}

ски распространить достижения наук о человеке, таких как психология, характерология, антропология и социология.

Структурный анализ и предложенная типология акторов в нарративной культуре представляют собой существенный шаг в сознании универсального культурологического метаязыка, пригодного для описания, анализа и реконструкции культурных феноменов самой различной природы. Очевидно, что структурный анализ акторов и предложенная типология акторов в нарративной культуре имеют большое культурологическое значение и нуждаются в дальнейшей разработке.

\section{Список литературъ:}

1. Барт Р. Нулевая степень письма. М.: Академический Проект, 2008.

2. Бахтин М.М. Эстетика словесного творчества. 2-е изд. М.: Искусство, 1986.

3. Бурбаки Н. Очерки по истории математики. М.: Изд-во иностранной литературы, 1963.

4. Бойко М.Е., Руднев В.П. Реализм и характер // Знание. Понимание. Умение. 2011. № 3.

5. Бойко М.Е. Метод структурного анализа характеров литературных персонажей: Апробация и первые итоги // Культура и искусство. 2012. № 1 (7).

6. Греймас А.Ж., Курте Ж. Семиотика: объяснительный словарь теории языка // Семиотика / Сост. Ю.С. Степанов. М.: Радуга, 1983.

7. Греймас А.Ж. Структурная семантика: Поиск метода. М.: Академический Проект, 2004.

8. Декомб В. Современная французская философия. М.: Весь Мир, 2000.

9. Карнап Р. Значение и необходимость: Исследование по семантике и модальной логике. 2-е изд. М.: ЛКИ, 2007.

10. Когнитивная психология / под ред. В.Н. Дружинина, Д.В. Ушакова. М.: ПЕР СЭ, 2002.

11. Леви-Строс К. Мифологики: Сырое и приготовленное. М.: Флюид, 2006.

12. Личко А.Е. Психопатии и акцентуации характера у подростков. СПб: Речь, 2010.

13. Лоуэн А. Физическая динамика структуры характера. М.: Компания ПАНИ, 1996.

14. Мартин Б., Рингхэм Ф. Словарь семиотики. М.: ЛИБРОКОМ, 2010.

15. Нёт В. Чарлз Сандерс Пирс // Критика и семиотика. 2001. № 3/4.

16. Пропп В.Я. Морфология волшебной сказки. М.: Лабиринт, 2001.

17. Райх В. Анализ характера. М.: Апрель Пресс, ЭКСМО-Пресс, 2000.

18. Руднев В.П. Прочь от реальности: Исследование по философии текста. М.: Аграф, 2000.

19. Скворцов В.А. Примеры метрических пространств. М.: Изд-во Московского центра непрерывного математического образования, 2002.

20. Уайт Л.А. Понятие культуры // Антология исследований культуры. Т. 1. СПб: Университетская книга, 1997.

21. Шмид В. Нарратология. 2-е изд. М.: Языки славянской культуры, 2008.

22. Шрейдер Ю.А. Что такое расстояние? М.: Физматгиз, 1963.

23. Юнг К.Г. Об энергетике души. М.: Академический Проект, 2010.

24. Ярхо Б.И. Методология точного литературоведения. М.: Языки славянских культур, 2006.

25. Osgood C.E., Suci G.J., Tanenbaum P.N. The Measurement of Meaning. Urbana: University of Illinois Press, 1957.

26. Peirce C.S. Collected Papers, vols. 1-6, ed. Hartshorne, C. \& P. Weiss, vols. 7-8, ed. Burks. A.W. Cambridge (Mass.): Harvard Univ. Press, 1931-1958.

27. Shepard R. Multidimentional scaling, free-fitting, and clustering // Science. 1980. Vol. 210. P. 390-398.

\section{References (transliteration):}

1. Bart R. Nulevaya stepen' pis'ma. M.: Akademicheskiy Proekt, 2008.

2. Bahtin M.M. Estetika slovesnogo tvorchestva. 2-e izd. M.: Iskusstvo, 1986.

3. Burbaki N. Ocherki po istorii matematiki. M.: Izd-vo inostrannoy literatury, 1963.

4. Boyko M.E., Rudnev V.P. Realizm i harakter // Znanie. Ponimanie. Umenie. 2011. № 3.

5. Boyko M.E. Metod strukturnogo analiza harakterov literaturnyh personazhey: Aprobaciya i pervye itogi // Kul'tura i iskusstvo. 2012. № 1 (7). 


\section{Структурализм}

6. Greymas A.Zh., Kurte Zh. Semiotika: ob’yasnitel'nyy slovar' teorii yazyka // Semiotika / Sost. Yu.S. Stepanov. M.: Raduga, 1983.

7. Greymas A.Zh. Strukturnaya semantika: Poisk metoda. M.: Akademicheskiy Proekt, 2004.

8. Dekomb V. Sovremennaya francuzskaya filosofiya. M.: Ves` Mir, 2000.

9. Karnap R. Znachenie i neobhodimost': Issledovanie po semantike i modal'noy logike. 2-e izd. M.: LKI, 2007.

10. Kognitivnaya psihologiya / Pod red. V.N. Druzhinina, D.V. Ushakova. M.: PER SE, 2002.

11. Levi-Stros K. Mifologiki: Syroe i prigotovlennoe. M.: Flyuid, 2006.

12. Lichko A.E. Psihopatii i akcentuacii haraktera u podrostkov. SPb: Rech', 2010.

13. Louen A. Fizicheskaya dinamika struktury haraktera. M.: Kompaniya PANI, 1996.

14. Martin B., Ringhem F. Slovar' semiotiki. M.: LIBROKOM, 2010.

15. Net V. Charlz Sanders Pirs // Kritika i semiotika. 2001. № 3/4.

16. Propp V.Ya. Morfologiya volshebnoy skazki. M.: Labirint, 2001.

17. Rayh V. Analiz haraktera. M.: Aprel' Press, EKSMO-Press, 2000.

18. Rudnev V.P. Proch' ot real'nosti: Issledovanie po filosofii teksta. M.: Agraf, 2000.

19. Skvorcov V.A. Primery metricheskih prostranstv. M.: Izd-vo Moskovskogo centra nepreryvnogo matematicheskogo obrazovaniya, 2002.

20. Uayt L.A. Ponyatie kul'tury // Antologiya issledovaniy kul'tury. T. 1. SPb: Universitetskaya kniga, 1997.

21. Shmid V. Narratologiya. 2-e izd. M.: Yazyki slavyanskoy kul'tury, 2008.

22. Shreyder Yu.A. Chto takoe rasstoyanie? M.: Fizmatgiz, 1963.

23. Yung K.G. Ob energetike dushi. M.: Akademicheskiy Proekt, 2010.

24. Yarho B.I. Metodologiya tochnogo literaturovedeniya. M.: Yazyki slavyanskih kul'tur, 2006.

25. Osgood C.E., Suci G.J., Tanenbaum P.N. The Measurement of Meaning. Urbana: University of Illinois Press, 1957.

26. Peirce C.S. Collected Papers, vols. 1-6, ed. Hartshorne, C. \& P. Weiss, vols. 7-8, ed. Burks. A. W. Cambridge (Mass.): Harvard Univ. Press, 1931-1958.

27. Shepard R. Multidimentional scaling, free-fitting, and clustering // Science. 1980. Vol. 210. P. 390-398. 